\title{
INFLUÊNCIA E SUPERAÇÃO NA POÉTICA DE RUY BELO
}

Ana Maria Pereira SOARES

\section{RESUMO}

O presente estudo pretende demonstrar que, para Ruy Belo, a dimensão hipertextual da poesia é uma inevitabilidade. No entanto, esta perceção não pressupõe uma atitude passiva face ao fenómeno da influência. Na sua perspetiva, o poeta que procura uma voz própria é aquele que convive com as vozes do passado para depois as defrontar e superar. A partir da análise de um excerto do poema A margem da alegria e do cotejo da obra de Dominique Saint-Alban, Le roman d'amour des grandes Égéries, procurar-se-á igualmente demonstrar o caráter hipertextual da escrita de Ruy Belo, assim como os dispositivos compositivos utilizados para obter uma elevada temperatura da expressão e desencadear a emoção estética.

Palavras-chave: Ruy Belo. Tradição. Hipertextualidade. Leitor.

No prefácio à segunda edição de Aquele grande rio Eufrates, primeiro livro de poesia de Ruy Belo, publicado em 1961, o autor assumia já nessa fase inicial da sua escrita a sua dimensão hipertextual ${ }^{1}$, revelando como principais influências a Bíblia, missais, Eliot, Saint-Exupéry. Em Boca bilingue, obra publicada em 1966, o poeta reafirma essa característica da sua poesia. Na verdade, no poema "Em cima de meus dias", integrado na secção da obra "Sete coisas verdadeiras", anuncia: "Nada na minha poesia é meu / juro por Deus dizer toda a verdade” (2014, p. 195). Em 1969, insurgindo-se contra a ideia da espontaneidade em poesia e defendendo

* Doutoramento em Estudos Literários, Culturais e Interartísticos, Ramo de Literatura e Cultura - Estética Literária, pela Faculdade de Letras da Universidade do Porto, Portugal.

E-mail: amsoares1819@gmail.com

1 "Livro, por outro lado, cheio de influências. A única coisa que jamais perdoei a um autor foi tê-lo lido, tê-lo até talvez estudado e não haver deixado a menor, a mais indirecta marca em tudo aquilo que escrevi" (BELO, 2014, p. 20). 
a necessidade de o poeta tardio ter de exercitar árdua e morosamente a capacidade de composição para que o poema se apresente com "cada peça no seu lugar, acabado, perfeito” (2002, p. 106), Ruy Belo apontava com naturalidade um dos processos prévios à criação, o de fazer "mão baixa na obra de outros poetas" (2002, p. 107). Esta defesa da escrita como trabalho hipertextual é retomada em 1972, no ensaio Da sinceridade em poesia. Leitor atento de T. S. Eliot e do seu programa para o métier de poesia, Ruy Belo insiste que o poeta tem a liberdade de se servir de "toda a obra publicada de todos os autores e até poetas” (2002, p. 321), isolando e excisando palavras ou segmentos de maior ou menor dimensão para criar um repertório que utilizará como material de construção do seu novo artefacto artístico. Tal como o agente florestal, descrito por Compagnon (1979, p. 27), que tinha o hábito de ler com as tesouras, recortando literalmente os livros e deixando somente aquilo que mais lhe agradava, a ponto de cada obra da sua biblioteca ficar reduzida à encadernação e a duas ou três folhas, a recolha de material compositivo seria um processo com uma finalidade idêntica. A leitura como mutilação do texto predecessor é uma etapa fundamental na génese do processo criativo. $\mathrm{O}$ recrutamento de palavras e expressões com potencial poético seria feito através da elaboração de fichas, de listagens de vocábulos improváveis ou do recurso a fragmentos sublinhados nas obras lidas.

Ruy Belo advoga, por conseguinte, uma arte poética assente na importância da leitura como ato de ablação. Os discursos predecessores são a fonte onde o poeta vai beber a influência, conhecendo-a, convivendo com ela, fazendo a sua avaliação, medindo o seu poder, para depois, servindo-se da matéria-prima excisada, se digladiar com os textos do passado e os superar num novo objeto compositivo. "Quanto mais livresca a poesia for, mais viva será” (BELO, 2002, p. 323), proclama, consciente da inevitabilidade da influência e da necessidade de partir do confronto e da medição de forças com os autores antigos para poder encontrar uma voz própria.

As fontes privilegiadas para se fazer a recolha linguística obedecem a critérios relevantes, pois procura-se promover a intensidade e a invulgaridade da expressão. Mais uma vez, Ruy Belo segue de perto os preceitos de T. S. Eliot a este propósito. Com efeito, o bom poeta é aquele que sabe usar "textos longínquos no tempo, estranhos no idioma, 
ou diversos no interesse" (ELIOT, [1944], p. 270). Escrever com esta matéria-prima proporciona igualmente ao poeta tardio uma panóplia de possibilidades de escrita e uma depuração técnica e estética que não deve ser descurada. Esta é a forma como os grandes poetas devem trabalhar, tomando consciência de que a influência é um facto inescapável e de que a sua escrita passa obrigatoriamente pelo conhecimento das vozes extintas, condição fundamental para poderem afirmar o seu talento individual. $\mathrm{O}$ seu objetivo não é serem imitadores do passado, mas conhecerem esse passado: os textos, os poetas e os escritores que se destacaram pela sua originalidade e capacidade de construir objetos de fruição estética, a fim de, partindo desse conhecimento profundo, delinearem o seu percurso. Ruy Belo tem consciência do peso da tradição enquanto mecanismo inevitável de influência. Como poeta tardio, sabe que está cercado pelas vozes antigas que compõem a identidade e constituem a memória coletiva do presente. Escreve, por isso, carregando sobre os ombros o peso esmagador da tradição, lutando e trabalhando arduamente as palavras para fugir à tirania da replicação do discurso e das imagens, e levar a sua voz a atingir a singularidade, conseguindo surpreender pelo inesperado da sua linguagem, pois os bons poetas, como advoga T. S. Eliot, convertem o material recolhido "em algo melhor ou, pelo menos, diferente" ([1944], p. 270). Esse laborioso exercício transformacional da matéria-prima previamente recrutada passa, na perspetiva de Ruy Belo, pela atenta observação da palavra, pela exploração de uma "nova arrumação" (2014, p. 360) que permita criar novas relações de contiguidade e de interinfluência. No entanto, a especificidade da poesia de Ruy Belo vai muito mais longe do que o poético recrutamento vocabular e a reimplantação das palavras e segmentos em contextos imprevistos. Uma multiplicidade de outros dispositivos transformacionais, utilizados verso após verso, fragmento após fragmento, contribuem para desencadear a visão estética e a temperatura da expressão da sua escrita.

O presente estudo irá debruçar-se sobre um dos hipotextos de onde o poeta recrutou material para a construção de um fragmento de 55 versos pertencente ao poema-livro $A$ margem da alegria ${ }^{2}$. Trata-se da obra de Dominique Saint-Alban, Le roman d'amour des grandes Égéries, uma fonte

A este propósito, veja-se SOARES (2017). 
pouco conhecida pelo público, logo de circulação restrita e de identificação mais difícil por parte da instância da receção, com a particularidade (que também não favorece a sua deteção) de estar escrita em língua francesa. Esta escolha ilustra a perspetiva do poeta sobre a questão da revelação das fontes. No ensaio As influências em poesia, defende que a grande poesia "não se sente obrigada a indicar a origem" da sua influência (BELO, 2002, p. 285), essa será uma tarefa que compete ao leitor ou ao crítico, evidenciando, deste modo, a relação de exigência que estabelece com o seu público. A obra que o poeta escolheu como hipotexto é constituída por 13 contos e debruça-se sobre um conjunto de Egérias, mulheres que marcaram e inspiraram a vida e obra de homens célebres da tradição literária, como Petrarca, Ronsard, Numa Pompílio, Molière, Diderot, Vigny, Benjamin Constant, Rousseau, Charles de Montauzier, Apollinaire, Racine, Chateaubriand, Lamartine.

O cotejo entre o hipotexto de Dominique Saint-Alban e a quinta secção da composição poemática $A$ margem da alegria permite verificar que Ruy Belo utilizou várias abordagens hipertextuais. A superação é sempre a nota dominante, não há utilização do material recrutado sem o desejo de prevalecer sobre o discurso precedente, pelo que o poeta, de acordo com as necessidades da elocução, seguiu diferentes estratégias compositivas. Um dos mecanismos transformacionais utilizados, como se poderá verificar, é a ablação cirúrgica de segmentos e a sua posterior tradução.

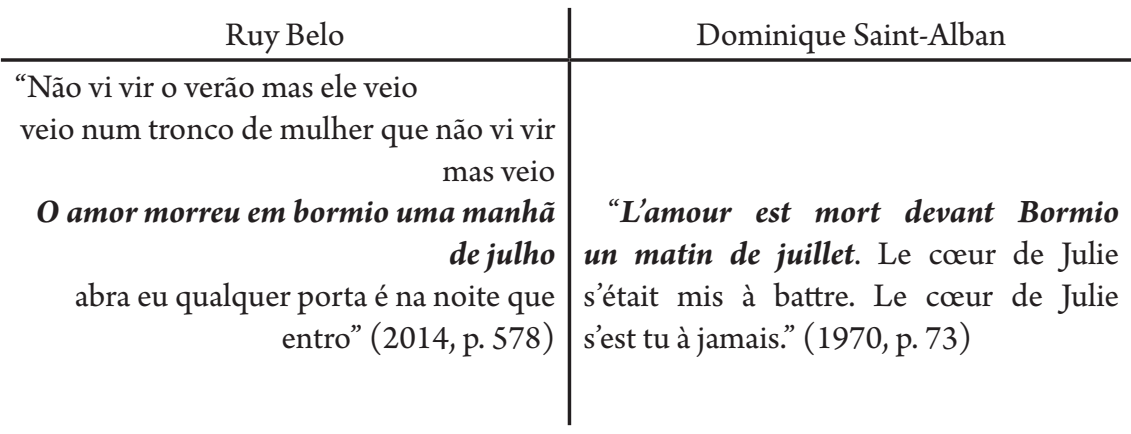

No exemplo apresentado, o poeta efetua a tradução do segmento extraído do hipotexto, contudo reimplanta-o meticulosamente numa 
nova e inesperada vizinhança. O contexto em que ocorre confere-lhe uma fulgurância invulgar e um elevado impacto estético. Apesar de tudo, o poeta recorre com pouca frequência a esta estratégia compositiva. De facto, são consideravelmente superiores o número de situações em que a matéria-prima selecionada é alvo de outro tipo de intervenções que põem em evidência a ressonância rítmico-emotiva do verso e a excecionalidade compositiva de Ruy Belo. Com efeito, há momentos em que o processo transformacional é quase impercetível, mas um subtil gesto de torneamento elevou de imediato a poeticidade do discurso.

\begin{tabular}{|c|c|}
\hline Ruy Belo & Dominique Saint-Alban \\
\hline $\begin{array}{r}\text { "vinte e um anos de amor vinte e um } \\
\text { anos de silêncio" (2014, p. 578) }\end{array}$ & $\begin{array}{l}\text { "Vingt et un ans d'amour et vingt et un ans } \\
\text { de silence." (1970, p. 30) }\end{array}$ \\
\hline $\begin{array}{r}\text { "amor nocturno de árvores e fontes" } \\
(2014, \text { p. 578) }\end{array}$ & $\begin{array}{l}\text { "C'est ici la rencontre nocturne des arbres } \\
\text { et des fontaines." (1970, p. 32) }\end{array}$ \\
\hline $\begin{array}{r}\text { "entre nós era a tarde e os quilómetros" } \\
(2014, \text { p. 578) }\end{array}$ & $\begin{array}{l}\text { "Ils ont cinquante ans bientôt l'un et l'autre, } \\
\text { séparés par des kilomètres, et le soir [...]." } \\
\text { (1970, p. 172) }\end{array}$ \\
\hline
\end{tabular}

No primeiro excerto, é possível verificar que, com a simples opção de retirar a conjunção copulativa "e", o poeta obteve uma maior fluidez do discurso, ao mesmo tempo que elevou para primeiro plano a construção paralelística, com implicações relevantes na cadência do verso e na perceção do tempo como uma longa barreira de silêncio separando os amantes. No exemplo seguinte, Ruy Belo transformou o sentido da expressão excisada do hipotexto, em resultado da substituição de "rencontre" pela palavra "amor", mantendo este sentimento como tema principal de reflexão. É efetuada uma outra mudança, mais subtil, no segmento extraído: a substituição da preposição contraída com o determinante artigo definido ("des"), repetida duas vezes no hipotexto, pela preposição simples "de", com uma única ocorrência no hipertexto. Os sintagmas "des arbres" e " 
des fontaines" eram complementos de relação ${ }^{3}$ de "rencontre" no texto de Dominique Saint-Alban. Com o desaparecimento do determinante, Ruy Belo transforma-os em complementos de caracterização, com a função de atributos: "amor nocturno de árvores e fontes" ${ }^{4}$. Como é evidente, o poeta não optou pelos adjetivos "arbóreo" ou "fontanal", uma vez que o verso resultaria verborreico e perderia fluidez. No entanto, a sua aguda atenção à palavra, aos seus contornos sonoros e às relações de interinfluência amplificou, com este delicado gesto de polimento, o impacto estético da expressão.

Na última situação transcrita, observa-se uma mudança da entidade responsável pela narração. No hipertexto, o discurso é assumido na primeira pessoa ("entre nós"), acentuando o tom lírico deste momento do poema. Por outro lado, utilizando o mesmo material, "tarde" e "quilómetros", o poeta insere-o em novas cercanias, levando-o imediatamente a estabelecer "novas ligações" (BELO, 2002, p. 83). Com o recurso a este dispositivo hipertextual, são expressos os mesmos sentimentos de distância e de separação, todavia, com uma temperatura poética que ultrapassa a do hipotexto.

A utilização de um leque alargado de diferenciados dispositivos transformacionais poderá ser igualmente observada na seguinte passagem do poema:

\begin{tabular}{|c|c|}
\hline Ruy Belo & Dominique Sant-Alban \\
\hline $\begin{array}{l}\text { "égira árvore ninfa às estações sujeita } \\
\text { que }\end{array}$ & $\begin{array}{l}\text { “[... ] ce roi amoureux de son arbre-nymphe, } \\
\text { l'étreignant avec passion, apprenant d'elle } \\
\text { l'amour et la vérité. } \\
\text { [...] Égérie connaissait le prix des rigidités, } \\
\text { des ordres fixes, des saisons. } \\
\text { [... ] Elle l'aidait en lui offrant ce qu'elle } \\
\text { avait de plus précieux : sa sagesse d'arbre." } \\
(1970, \text { p. } 18-19)\end{array}$ \\
\hline
\end{tabular}

3 Cf. GOOSSE, 1986, p. 563-565.

$4 \quad$ "La disparition du déterminant dans le complément transforme le complément de relation en complément de caractérisation. [... ] Les syntagmes servant de compléments de caractérisation peuvent souvent être employés comme attributs" (GOOSSE, 1986, p. 565). O mesmo autor considera que a língua literária utiliza com frequência este tipo de construções, em vez de epítetos, por imitação do estilo bíblico. 
Tal como nos exemplos analisados anteriormente, verificase que as palavras recrutadas do hipotexto foram colocadas numa diferente combinatória. Porém, um olhar mais atento sobre as escolhas compositivas do poeta permite observar todo um trabalho apurado sobre as virtualidades da linguagem. Nesta situação precisa, Ruy Belo optou por não incluir a tradução do segmento "connaissait le prix [... des saisons", uma vez que teria uma ressonância inteiramente prosaica. Assim, utilizando apenas o vocábulo "estações”, recriou o que foi dito pelo autor precedente, mas procurando obter um maior grau de poeticidade. A inversão da ordem das palavras no novo segmento ("às estações sujeita”) foi o último gesto de manipulação e polimento para aumentar o seu impacto estético. Para além destas estratégias compositivas, verifica-se que, no limite do primeiro verso transcrito, surge isolado e suspenso o pronome relativo "que", convertido em rutura inesperada da integridade da frase e terminando de forma desconcertante esta unidade rítmica. O hiato produzido pela não coincidência entre a unidade da sintaxe e o limite do verso imprime a este último uma cadência invulgar e despoleta a estranheza e a perceção estética. $\mathrm{O}$ ritmo e a musicalidade do discurso são igualmente acentuados pelo recurso a outros dispositivos, como a rima interna ("numa", "suma"), a aliteração ("sua suma sabedoria"), o jogo com diferentes timbres vocálicos ("oferecia a numa a sua suma sabedoria”). Todas estas transformações permitem confirmar que Ruy Belo visava efetivamente suplantar e obscurecer o discurso predecessor, jogando com a criação de novas vizinhanças e relações de interinfluência e com as virtualidades sonoras das palavras, a fim de que cada verso concentrasse uma forte energia rítmico-emotiva.

A análise do cotejo entre hipotexto e hipertexto permite chegar a outra conclusão relevante sobre as estratégias transformacionais utilizadas por Ruy Belo. Com efeito, considerando que a poesia é "uma leitura vivificadora de determinada obra” (2002, p. 284), há fragmentos do poema em que se torna nítido que o poeta interpreta e depois transforma o que leu previamente. Mais do que um processo de recolha de uma coleção de materiais para se criar um novo objeto artístico, trata-se, nestes momentos, 
de um processo de leitura e de posterior recriação. Como se tivesse o livro diante de si, o poeta colhe agora menos palavras e segmentos, porque o seu objetivo principal é reescrever o texto anterior, medindo forças com o autor antigo, entrando em confronto com ele para que o seu novo artefacto artístico ensombre o discurso predecessor.

\begin{tabular}{|c|c|}
\hline Ruy Belo & Dominique Sant-Alban \\
\hline $\begin{array}{r}\text { “Quando um dia soube da morte de } \\
\text { numa } \\
\text { égira começou a contorcer-se a sacudir } \\
\text { os ramos } \\
\text { a morrer e a sofrer por não saber a forma } \\
\text { humana de chorar } \\
\text { égira árvore égira fonte fonte para } \\
\text { sempre } \\
\text { fonte de cujas águas podem emergir } \\
\text { nereidas } \\
\text { a chorar para sempre a morte desse nebuloso } \\
\text { rei” }(2014, \text { p. } 577)\end{array}$ & $\begin{array}{l}\text { "Lorsque Numa mourut, Egérie } \\
\text { poussa un cri terrible. Les forêts tout } \\
\text { autour s'effrayèrent. [...] dans le Bois } \\
\text { d'Aricie un arbre se tordait, secouait } \\
\text { ses branches, arrachait ses feuilles, } \\
\text { et le tronc se pliait en deux. [...] } \\
\text { Mais cet arbre seul parmi les arbres, } \\
\text { se débattait en hurlant. Ses branches } \\
\text { se brisaient. Son écorce tombait } \\
\text { par plaques. C'était des blessures, } \\
\text { des plaies vives. Les autres [...] } \\
\text { supplièrent Diane d'intervenir. [...] } \\
\text { - Que veux-tu? demanda-t-elle. [...] } \\
\text { - Pleurer, répondit la nymphe. } \\
\text { Pleurer comme pleurent lesfemmes. } \\
\text { Toutes ces larmes en moi qu'un } \\
\text { arbre ne peut pas verser... } \\
\text { Diane l'entendit et la changea en } \\
\text { fontaine." (1970, p. 21) }\end{array}$ \\
\hline
\end{tabular}

Este exemplo confirma a perspetiva, salientada por Ruy Belo no prefácio à segunda edição de Aquele grande rio Eufrates, de que o poeta é, antes de tudo, um leitor-autor ${ }^{5}$. Na verdade, no conto de Dominique SaintAlban, Egéria, "símbolo da mulher que ama com amor" (BELO, 2014, p. 577), tendo recebido a notícia da morte de Numa, experimenta um sofrimento atroz. A descrição desse pathos no hipotexto conduz o poeta a procurar expressá-lo através da utilização depurada de um conjunto

5 "Mas para quê, pergunto eu, fornecer a essoutro autor que afinal é o leitor ou o crítico um elemento que só poderá servir para desnortear?” (2014, p. 21) 
de mecanismos compositivos, a fim de elevar a poeticidade do discurso e despoletar a emoção estética. Por conseguinte, a leitura deste excerto do hipotexto levou Ruy Belo a ambicionar desafiar o texto precedente, no sentido de apresentar uma reescrita do mesmo, capaz de desencadear a emoção estética. Assim, os verbos "a morrer e a sofrer" são utilizados para sintetizar a descrição da reação da ninfa face à inelutabilidade da sua perda: os gritos, os ramos partidos, as folhas arrancadas, a casca que cai em pedaços, deixando no tronco as marcas dos ferimentos sentidos, das chagas abertas. $O$ poeta não se detém nesta enumeração das consequências da notícia da morte de Numa. No verso, "égira árvore égira fonte fonte para sempre", com grande precisão e economia de vocábulos, traduz de forma intensamente lírica a transição da ninfa de "árvore" para "fonte" que chora, vertendo eternamente as lágrimas de luto pela morte do seu "nebuloso rei". Tal transição não é explicada no poema. Não é necessária. As relações de contiguidade e de interinfluência das palavras no verso tornam-na visível, fruto de uma extraordinária capacidade de examinar e contemplar as palavras nos seus mais diversos ângulos e de as dispor no verso de forma a atingirem o máximo poder de expressão. Por outro lado, são esgotadas as possibilidades musicais do verso, através da repetição da palavra "égira" e da criação de uma palilogia, patente na geminação da palavra "fonte", cujo efeito de eco se estende até ao início do verso seguinte, realçando-se a profundidade do sofrimento da ninfa, diante dessa rutura definitiva que é a morte. Outros mecanismos são utilizados, no excerto do poema transcrito, para explorar a cadência rítmico-emotiva do verso e desencadear elevados níveis de energeia no poema, nomeadamente: a acumulação de verbos ("começou a sacudir os ramos / a morrer e a sofrer por não saber a forma humana de chorar"), logo seguida da acumulação de nomes ("égira árvore égira fonte fonte para sempre"); o jogo com os timbres vocálicos ("a sacudir os ramos / a morrer e a sofrer por não saber a forma humana de chorar"); a rima interna ("a morrer e a sofrer por não saber").

A análise do cotejo entre hipotexto e hipertexto permite chegar a uma outra conclusão interessante, no que se refere à forma como o 
poeta se debruça sobre o hipotexto. Efetivamente, verifica-se que o poeta vai seguindo inicialmente o decorrer dos acontecimentos relatados no texto predecessor, utilizando estratégias hipertextuais diversificadas, como as que já foram mencionadas. Este facto aplica-se plenamente à abordagem do conto sobre Numa Pompílio. Porém, no final da narração da história de amor entre o imperador e a ninfa Egéria, o poeta opta por uma outra técnica compositiva. De facto, começa a operar saltos para a frente e para trás no hipotexto, a fim de recolher segmentos mais distantes, pertencentes com frequência a outros contos. Estes avanços e recuos na excisão do material recrutado da obra de Dominique de Saint-Alban tornam-se uma constante. Os saltos podem variar entre uma página, dezenas de páginas ou mais de uma centena de páginas. Em consequência desta errância, deteta-se um entrelaçamento intricado entre os contos, ditado pelas necessidades compositivas do poema, que dificulta ao leitor ou ao crítico a identificação da influência, pois, quebrado o fio condutor dos contos narrados, permanece apenas um amontoado de palavras e expressões arrancadas do seu contexto inicial, como se o hipotexto tivesse sido britado e pulverizado, tornando difícil ao crítico reconstituir o lugar primitivo a que cada palavra pertencia. Sublinhe-se, contudo, que estes percursos de errância no recrutamento da matéria-prima desencadeiam descontinuidades e ruturas no hipertexto poemático de forte impacto estético. Observe-se, por exemplo, o seguinte excerto:

amor nocturno de árvores e fontes

palavra aprendizagem do silêncio

sei o teu nome sei tudo de ti

Não vi vir o verão mas ele veio

veio num tronco de mulher que não vi vir mas veio

$\mathrm{O}$ amor morreu em bormio uma manhã de julho

abra eu qualquer porta é na noite que entro

e choro o meu verão e choro a minha idade

o ferimento ardente da coragem

brisa vizinha em nice e no ópio de guillaume apollinaire (BELO, 2014, p. 578) 
Nos versos transcritos, verifica-se que o poeta circula entre cinco diferentes contos, pertencentes ao já referido hipotexto Le roman d'amour des grandes Égéries, de Dominique Saint-Alban, nomeadamente:

$\begin{array}{ll}\text { Verso } 1 & \text { "Laure de Noves et Pétrarque" } \\ \text { Verso } 2 & \text { "Les amours de Ronsard" } \\ \text { Verso } 3 & \text { "La Champmeslé et Racine" } \\ \text { Versos } 4 \text { e } 5 & \text { "Les amours de Ronsard" } \\ \text { Verso } 6 & \text { "Julie d'Angennes et sa guirlande" } \\ \text { Versos } 7 \text { e } 8 & \text { "Les amours de Ronsard" } \\ \text { Versos } 9 \text { e } 10 & \text { "Louise de Coligny-Châtillon et } \\ & \text { Guillaume Apollinaire" }\end{array}$

Os materiais provenientes do conto sobre os amores de Ronsard são retomados por três vezes, de forma intercalada, misturando-se e entrelaçando-se com o repertório dos contos sobre Laura e Petrarca, Racine, Julie d'Angennes, Apollinaire. A dispersão que este recrutamento vocabular parece evidenciar mostra o quão árduo e longo é o trabalho de construção do poema. Obedecendo às necessidades compositivas do novo artefacto artístico e ao desejo de obter uma elevada temperatura da expressão, o poeta leva a exploração da musicalidade das palavras e das suas interinfluências ao limite das suas possibilidades, pelo que, face a este ofício exigente e moroso, Ruy Belo recusa a ideia de espontaneidade em poesia, sublinhando que “[...] espontâneo é Mallarmé. Aí o temos, com cada peça no seu lugar, acabado, perfeito. Mas o pior é nós sabermos o tempo e o esforço que essa espontaneidade custou” (2002, p. 106).

É evidente que, no excerto transcrito, este complexo dispositivo de recolha não sequencial de material, por si só, não garante a intensidade estética, pelo contrário o discurso seria verborreico e destituído de vitalidade. Como já se pôde observar, são variados os processos utilizados pelo poeta para, cumulativamente, conduzirem o verso a níveis máximos de energia, e este excerto do poema não é exceção. Assim, é possível observar, no primeiro, segundo e último versos, a acumulação de nomes 
que criam ligações inesperadas e elevam a temperatura da expressão. Estão igualmente presentes vários efeitos rimáticos e formas de repetição: a rima interna ("sei"); a rima interna e externa ("veio"); a rima aliterante ("veio num tronco de mulher que não vi vir mas veio"); o poliptoto ("vir", "veio"); o jogo com os timbres vocálicos ("O amor morreu em bormio uma manhã de julho"); o paralelismo ("e choro o meu verão e choro a minha idade"). Os mecanismos mencionados, juntamente com as descontinuidades promovidas pela errância da recolha de matéria-prima contribuem para um elevado grau de codificação da influência assim como para a desejada amplificação térmica do discurso poemático.

Não obstante, Ruy Belo utiliza outros processos de codificação da influência, igualmente desafiantes. Como já se referiu anteriormente, o poeta considera a hipertextualidade um princípio indissociável da grande poesia; no entanto, tal perspetiva não significa que se sinta obrigado a desvendar as fontes utilizadas, essa será uma tarefa do leitor ou crítico. Ruy Belo reconhece tratar-se de um trabalho "meritório" (2002, p. 286) e de grande exigência, mas em nenhum momento faz concessões à instância da receção, como se poderá observar nos versos seguintes:

Só uma elvira de momento existe não te escrevo uma carta mando-te o meu nome a morte chega na forma de fogo (2014, p. 578)

Os indícios para a identificação do texto de onde Ruy Belo terá selecionado material são claros: Elvira, a carta, a morte pelo fogo remetem para a influência da obra $D$. Juan, de Molière. O leitor acredita. O poeta concedeu-lhe generosamente estas pistas, por isso segue-as com atenção, porém rapidamente se apercebe de que não é possível estabelecer uma conexão com os fragmentos anteriores nem com os subsequentes, e o leitor fica ainda mais confuso e perdido, sem saber que direção tomar. De facto, o caminho sugerido no poema conduz a um beco sem saída. $\mathrm{O}$ material transformado não foi recrutado dessa obra. Trata-se de um mecanismo ilusivo comum na escrita de Ruy Belo que potencia uma ambiguidade 
fecunda do discurso, ao mesmo tempo que contribui para a desorientação da instância da receção e para a dificultação da leitura em profundidade do poema, pois o leitor pode intuir em transparência a existência de um hipotexto, mas não há um fio de Ariadne que o oriente. Aliás, existe um fio condutor cedido pelo poeta, todavia, mergulha ainda mais o leitor no profundo labirinto de vozes e de influências que atravessam o discurso poemático A margem da alegria. Efetivamente, nesta situação concreta, o repertório foi recolhido da obra Le roman d'amour des grandes Égéries. Os versos foram intencionalmente justapostos e cada um deles possui material recortado dos contos: "Julie Charles e Lamartine" ("- Désormais il n'y a qu'une Elvire"); "Marie Dorval e Alfred de Vigny" ("Je ne t'écris pas de lettre. Je t'envoie seulement mon nom"); e "Charlotte de Hardenberg et Benjamin Constant" ("Pour la rejoindre quinze ans plus tard, la mort prend l'apparence du feu”) (1970, p. 245, 272 e 199 respetivamente).

Assim, o que foi excisado de um determinado hipotexto e alvo de recomposição gera uma nova alusão, que aponta para outra influência possível, da qual o poeta não recolheu qualquer material compositivo. Esta exímia capacidade de criar mecanismos ilusivos que confundem e desnorteiam o leitor é mais um processo utilizado não só para aumentar o impacto estético, mas também para elevar o grau de codificação do poema e a sua dimensão desconcertante. O indício que o poeta efetivamente deixa transparecer é aquilo que ele designa como uma "falsa pista", estratégia que, no seu poema "Estudo", reconhece utilizar com frequência:

Esta incorrigível mania de trocar coisa por coisa que faz com que eu repita a mesma palavra para falar de realidades diferentes esta pista - falsa pista - para alguém que eventualmente queira conhecer o pensamento de quem afinal só esperava uma carta (BELO, 2014, p. 306-307)

Por outro lado, Ruy Belo pretende demonstrar como é fácil, com palavras provenientes de um dado autor, evocar as palavras de outros autores, provando, deste modo, que os discursos estão em contínua 
relação e que a escrita é um permanente exercício de reescrita, pois as palavras que o poeta tardio utiliza são as palavras já utilizadas por todos ao longo dos tempos. Cabe-lhe a ele encontrar uma forma de conciliar essa pesada herança da tradição, sombra que o assombra e ensombra, com a construção de uma voz própria.

É importante notar, por fim, que a hipertextualidade em Ruy Belo, que implica o recrutamento prévio de um repertório vocabular a partir de discursos anteriores, contribui também para garantir a elevada temperatura informacional da sua escrita. A quantidade e a diversidade lexical diminuem a redundância e aumentam as possibilidades combinatórias. $\mathrm{O}$ novo artefacto resultará mais surpreendente, uma vez que congrega termos de áreas e fontes diferentes e distantes, e essa coabitação gera estranheza, mas também uma riqueza de sentidos e de efeitos estéticos. Um número significativo de palavras ou expressões, selecionadas do Roman d'amour des grandes Égéries, possui uma única ocorrência ao longo d' A margem da alegria, corroborando essa alta temperatura informacional do poema. São elas: "pompílio", "roma”, "porta capena”, "bosque de ariccia”, "sabedoria”, "templo de janus”, “março”, “juno”, “contorcer-se”, "nereidas”, “nebuloso”, “aprendizagem”, “bormio”, "ferimento ardente”, “nice”, “ópio”, "guillaume apollinaire”, "lacrimosa”, “vigny”, "soneto”, "marie dorval”, "elvira”, "hélène de surgères", "charlotte hardenberg”, "molière”, entre outras. Não obstante, observada em si mesma, esta coleção de vocábulos é insípida, desconexa e destituída de potencial poético. A forma como Ruy Belo converte este repertório em grande poesia testemunha a sua genialidade compositiva, capaz de transformar uma amálgama de material acromático num discurso capaz de desencadear "emoções quentes" (BELO, 2002, p. 322).

Para concluir, poder-se-á afirmar que, após a análise, ao longo do presente estudo, da dimensão hipertextual da escrita de Ruy Belo e de alguns dos mecanismos compositivos utilizados pelo poeta, a sua relação com a influência é de aceitação da sua inevitabilidade. No entanto, trata-se de uma aceitação que procura vencer esse ensombramento das vozes antigas sobre o poeta tardio. Tendo em vista a procura de uma voz própria, o poeta procura, antes de mais, situar-se em relação à tradição, 
estudando-a, analisando as suas virtualidades, convivendo com ela. Sem nunca negar o ascendente das vozes extintas, digladia-se com elas e procura incansavelmente prevalecer sobre os discursos do passado, incendiando o leitor com a sua escrita e despertando a emoção estética, capaz de fazer "desabar cidades" (BELO, 2002, p. 322).

INFLUENCE AND OVERCOMING IN THE POETIC OF RUY BELO

\section{Abstract}

For Ruy Belo, the hypertextual dimension of poetry is an inevitability. However, this perception does not presuppose a passive attitude towards the phenomenon of influence. In his view, the poet who seeks a voice of his own must coexist with the voices of the past to later confront and overcome them. The analysis of an excerpt from the poem $A$ margem da alegria and the collation of Dominique de Saint-Alban's book, Le roman d'amour des grandes Égéries, will also seek to demonstrate the hypertextual characteristics of Ruy Belo's writing, as well as the compositional devices used by the poet to obtain a high temperature of expression and trigger aesthetic emotion.

KeYwords: Ruy Belo. Tradition. Hypertextuality. Reader.

INFLUENCIA Y SUPERACIÓN EN LA POÉTICA DE RUY BELO

\section{RESUMEN}

En este estudio se pretende demostrar que, para Ruy Belo, la dimensión hipertextual de la poesia es una inevitabilidad. Sin embargo, esta percepción no presupone una actitud passiva ante el fenómeno de la influencia. En su opinión, el poeta que busca una voz propia es aquel que convive con las voces del pasado para luego afrontarlas y superarlas. El análisis de un extracto del poema $A$ margem da alegria y de la colación del libro de Dominique Saint-Alban, Le roman d'amour des grandes Égéries, se buscará igualmente demostrar el carácter hipertextual de la escritura de Ruy Belo, así como los recursos compositivos utilizados para obtener una alta temperatura de expresión y desencadenar la emoción estética.

Palabras Clave: Ruy Belo. Tradicion. Hipertextualidad. Lector. 
BELO, Ruy. Na senda da poesia. Lisboa: Assírio \& Alvim, 2002.

BELO, Ruy. Todos os poemas. Lisboa: Assírio \& Alvim, 2014.

COMPAGNON, Antoine. La Seconde Main ou Le Travail de la Citation. Paris: Éditions du Seuil, 1979.

ELIOT, T. S. Ensaios de doutrina crítica. Lisboa: Guimarães Editores, 1997.

ELIOT, T. S. Los poetas metafísicos y otros ensayos sobre teatro y religión. Buenos Aires: Emecé Editores S. A., [1944], Tomo I.

GOOSSE, André. Le bon usage. Paris-Gembloux: Duculot, 1986.

SAINT-ALBAN, Dominique. Le roman d'amour des grandes Égéries. Paris: Robert Laffont, 1970.

SOARES, Ana Maria Pereira. A alegria e o mal em Ruy Belo: estudo da composição hipertextual d'A Margem da Alegria. 2017. 733 f. Tese (Doutoramento em Estudos Literários, Culturais e Interartísticos, Ramo de Literatura e Cultura Teoria e Estéticas Literárias) - Faculdade de Letras da Universidade do Porto, Porto, 2017.

Submetido em 28 de setembro de 2020

Aceito em 08 de outubro de 2020

Publicado em 14 de fevereiro de 2021 